\title{
A commentary on a flawed public health investigation
}

\author{
John Hardie*
}

\begin{abstract}
The possibility of hepatitis $C$ being transmitted between dental patients was the genesis of an extensive and expensive look-back investigation conducted by an Ontario Public Health Unit. This investigation was performed with a minimal knowledge of nosocomial infections of dental origin, an enthusiastic reliance on untested checklist indicators and an absence of any of the criteria justifying such an investigation. As a consequence, the entire exercise was based on the false premise that an infection control lapse had occurred. This commentary will address these flaws, and other aspects of the Public Health Unit's response that detracted from its credibility. The provision of a realistic assessment of disease transmission in dentistry should result in Public Health Units conducting informed and mutually beneficial inspections of dental practices.
\end{abstract}

Suggested citation: Hardie J. A commentary on a flawed public health investigation. Can Commun Dis Rep 2021;47(11):500-2. https://doi.org/10.14745/ccdr.v47i11a10

Keywords: public health, dentistry, nosocomial infections, IPAC lapse
This work is licensed under a Creative Commons Attribution 4.0 International License.

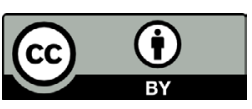

\begin{abstract}
About the author:
John Hardie is a retired Oral Pathologist. He was Head of Dentistry at the Ottawa Civic Hospital and Vancouver General Hospital and served in a similar capacity at hospitals and health trusts in Saudi Arabia and Northern Ireland. For over 35 years, he has lectured and published extensively on infection control as it relates to dentistry.
\end{abstract}

*Correspondence:

jhardie5@bell.net

\section{Introduction}

The article, "A public health response to a newly diagnosed case of hepatitis $C$ associated with lapse in Infection Prevention and Control Practices in a dental setting in Ontario, Canada" by Johnston et al. was published in the July/August 2021 edition of the Canada Communicable Disease Report (1). The article was written from a public health perspective with a minimal appreciation of dental procedures and dental infection control. As a consequence, the article provides a biased impression of hepatitis $C$ transmission in dentistry.

In 2019, a survey was published in the Canada Communicable Disease Report demonstrating that the staff of Ontario Public Health Units lacks the knowledge, training and expertise to appropriately investigate alleged infection prevention and control lapses (IPAC) occurring in health settings such as dental practices (2). Despite these damning conclusions, such inspections continue unabated with findings that are unsatisfactory for all concerned.

Major reasons for this include misinformation on disease transmission in dentistry, failure to appreciate the vulnerability of blood-borne viruses and an over reliance on checklist audits. By addressing these and related topics this commentary will illustrate the faults in the above article while offering a realistic assessment of hepatitis $C$ transmission in dental practice.

\section{Disease transmission in dentistry}

The following is a brief summation of the reality of disease transmission in dentistry.

- A 1993 conclusion that, "The lack of epidemiological evidence of transmission of infectious diseases on dental instruments and handpieces must be remembered, particularly when assessing a laboratory study." (3).

- There are no confirmed cases of human immunodeficiency virus (HIV), hepatitis $B$ virus (HBV) or hepatitis $C$ virus (HCV) being transmitted in Canadian dental practices (4).

- A 44 year investigation (1946-1990) of health care facilities (before the present era of infection control recommendations) failed to find a single case of cross contamination from dental instruments (5).

- A 2010 extensive review in the United Kingdom found no evidence of dental services causing the transmission of infections (6).

- A 2013 report on the transmission of HCV in an oral surgery practice was, as admitted by the investigators, based on pure speculation (7).

- A 2016 United States investigation covering a 12-year period found not a single case of HIV transmission linked to a dental practice and failed to clinically substantiate that presumptive transmissions of $\mathrm{HBV}$ and $\mathrm{HCV}$ were due to failures in dental infection control (8). 
- In 2018, the suspected transmission of bacterial endocarditis in an oral surgery practice was likely related to the inadequate preparation, storage and use of intravenous medications rather than to alleged IPAC lapses involving instruments (9).

From the 1940s to the present there have been billions of dental treatments performed-most without the current infection control protocols. As shown above, historical and current investigations have failed to reveal that dental instruments were vectors for the transmission of infections. In their haste to conduct the alleged IPAC lapse investigation the authors of the article did not perform a thorough review of the pertinent literature.

\section{Vulnerability of bloodborne viruses}

According to the Ontario Agency for Health Protection and Promotion (OAHPP), "Low-level disinfection eliminates vegetative (live) bacteria, some fungi and enveloped viruses." (10). Hepatitis C virus is a lipid-enveloped virus that is readily destroyed by the common disinfectants that have been used by generations of dentists. Do the article's authors believe that the HCV would survive physical cleaning, immersion in a low level disinfectant and the harsh environment of a steam sterilizer-even if it was operating at less than $100 \%$ efficiency?

HIV and HBV are also lipid-enveloped viruses. This fact, combined with the low pathogenicity of oral microorganisms, is the reason why there is an absence of clinically-substantiated evidence that dental instruments transmit infections. It is unfortunate that public health officials continue to ignore these data.

\section{Reliance on checklist audits}

Public Health Ontario checklists were used to determine if IPAC lapses had occurred. These lists contain approximately 100 indicators whose adoption is supposed to prevent and/or control dentally acquired infections. OAHPP demands that such indicators are, "...based on validated evidence that has been demonstrated to improve outcomes" (9). In other words, there must be clinical evidence of disease transmission prior to the use of the indicator that was prevented or controlled following the indicator's adoption.

The article cites 14 deficient indicators to justify the presence of IPAC lapses. Among these were the inconsistent use of chemical indicators, the incomplete record keeping and the improper cleaning of dental handpieces. However, there are no clinical studies that demonstrate that these and the other checklist failures cause nosocomial infections of dental origin that were avoided by complying with the indicators. The reality is that the checklists have not been validated. This should not be surprising as Nicolle noted in the Canadian Journal of Infectious Diseases that, "Infection control interventions have yet to be validated in health care settings outside of acute care." (11).

Without the validation that OAHPP requires, IPAC lapses cannot be identified; and without such identification, it is inappropriate and disingenuous to suggest in the article's title that one exists.

\section{Related topics}

The following issues further detract from the article's credibility.

- Uniqueness of hepatitis C-genotype 2: The reported rate for hepatitis $C$ in Ontario is 36.5 per 100,000 with $10 \%-15 \%$ of those being genotype 2 (12). With a population of 15 million there will be approximately 550 to 800 cases of hepatitis genotype 2 . This detracts from the authors' frequent assertions that the rarity of genotype 2 imparts a uniqueness to their article.

- Risk categories: The socioeconomic status of the involved patients is not known. However, they were treated at community dental clinics, which would question their reliability as historians of their health, sexual and recreational activities necessitating a thorough investigation of their risk factors for hepatitis $\mathrm{C}$. This is not mentioned in the article, instead there is a passing reference to the fact that the index patient had no, "...reported current or past risk factors related to HCV infection" (1).

- Look-back investigation: The article describes a look-back investigation. Dr. Danila and his team categorized these as expensive and limited in their ability to demonstrate transmission because of the relatively small number of patients studied and a low risk of transmission (13). This investigation consumed 1,187.5 hours, which could translate into a bountiful supply of taxpayer money. The authors admit that there is "...minimal scientific evidence of transmission of HCV in dental practice". This admission alone should have cast doubts on the success of the investigation. Three criteria justify look-back investigations (13): 1), definite evidence of disease transmission to a patient; 2), egregious violations of infection control; and 3), as part of a collaborative study. This investigation satisfies none of these qualifiers.

- Editing errors: In the Case definition section, the days before and after the procedure are classified as "business" days. However, in the Discussion section "business" is absent. In the Results section the source case is described as, "the probable source case". In the Discussion sectionwithout any rational justification-this has morphed into being the definitive, "source case". 
- Impossible hypothesis: In the Introduction, the HCV outbreak is downgraded to a "potential" outbreak and the exposures to HCV are deemed "potential" exposures. This means that the authors' hypothesis should read, "... a potential HCV transmission may have occurred at Facility $B$ potentially between the probable source case and the index case". The bolded corrections are such that it would be impossible to test the hypothesis making it invalid.

\section{Dentistry and hepatitis C}

Endoscopes are heavily contaminated during use and their complicated design results in reprocessing errors. Dental instruments are simpler in design, not subjected to the same bioburden and are often used for non-invasive procedures. Investigations on the risk of improperly reprocessed ear nose and throat endoscopes transmitting bloodborne infections serve as worst case scenarios for IPAC lapses during the decontamination of dental instruments. Such studies have shown that the risk of transmitting HIV is seven in 10 trillion, for HBV it is 2.4 in a billion and for HCV it is between that for HIV and HBV (13). These findings prove that there is an infinitesimal risk of contracting blood borne infections, including hepatitis $\mathrm{C}$, from dental instruments. The authors appear to be unaware of these risk assessments.

\section{Conclusion}

The public health response was an administrative exercise as it was not based on an actual HCV outbreak but a potential one. While it involved over a thousand staff hours, it was flawed in that it relied on non-validated checklists, it had no clinical justification for conducting the look back investigation, it exaggerated the uniqueness of the case and it was based on a hypothesis that cannot be tested. The authors' peers will judge the value of the response to an unproven IPAC lapse.

As explained above, there are historical and factual reasons why there are a dearth of clinically-substantiated disease transmissions from dental instruments. Perhaps, public health officials will use these reasons to consider the reality of disease transmission in dentistry-allowing them to conduct more informed investigations of dental practices in the future.

\section{References}

1. Johnston C, Sunil V, Ser D, Holt AM, Garber G, Macdonald L, Kristjanson E, Mazzulli T, Olsha R, Ryding D, Noseworthy AL. A public health response to a newly diagnosed case of hepatitis $\mathrm{C}$ associated with lapse in Infection Prevention and Control practices in a dental setting in Ontario, Canada. Can Commun Dis Rep 2021;47(7-8):347-52. DOI PubMed
2. Cadieux G, Brown C, Sachdeva H. Public health investigation of infection prevention and control complaints in Ontario, 2015-2018. Can Commun Dis Rep 2019;45(11):289-95. DOI PubMed

3. Epstein JB, Rea G, Sibau L, Sherlock CH. Rotary dental instruments and the potential risk of transmission of infection: herpes simplex virus. J Am Dent Assoc 1993;124(12):55-9. DOI PubMed

4. Hardie J. The Surprising Absence of Disease Transmission from Infection Control Disasters. Oral Health 2015;14-8. https:// www.oralhealthgroup.com/features/the-surprising-absence-ofdisease-transmission-from-infection-control-disasters/

5. Goodman RA, Solomon SL. Transmission of infectious diseases in outpatient health care settings. JAMA 1991;265(18):237781. DOI PubMed

6. Fox C. Evidence summary: what 'cost of illness' evidence is there about cross-infection related infections in dental practice? Br Dent J 2010;209(2):87-8. DOI PubMed

7. Weaver JM. Confirmed transmission of hepatitis $C$ in an oral surgery office. Anesth Prog 2014;61(3):93-4. DOI PubMed

8. Cleveland JL, Gray SK, Harte JA, Robison VA, Moorman AC, Gooch BF. Transmission of blood-borne pathogens in US dental health care settings: 2016 update. J Am Dent Assoc 2016;147(9):729-38. DOl PubMed

9. Ross KM, Mehr JS, Greeley RD, Montoya LA, Kulkarni PA, Frontin S, Weigle TJ, Giles H, Montana BE. Outbreak of bacterial endocarditis associated with an oral surgery practice: new Jersey public health surveillance, 2013 to 2014. J Am Dent Assoc 2018;149(3):191-201. DOI PubMed

10. Public Health Ontario. Provincial Infectious Diseases Advisory Committee (PIDAC). Best Practices for Infection Prevention and Control Programs in Ontario. In All health Care Settings, $3^{\text {rd }}$ edition. Toronto, ON: PHO; (updated 2012-05). https:// www.publichealthontario.ca/-/media/documents/B/2012/bpipac-hc-settings.pdf

11. Nicolle LE. Infection control in acute care facilities: evidence-based patient safety. Can J Infect Dis 2001;12(3):131-2. DOI PubMed

12. Public Health Ontario. Hepatitis C in Ontario, 2018: Surveillance summary one year after a case definition update. Toronto (ON): PHO; 2020 (accessed 2020-09-30). https://www. publichealthontario.ca/-/media/documents/r/2020/reporthepc-surveillance-2018.pdf?la=en

13. Danila RN, MacDonald KL, Rhame FS, Moen ME, Reier DO, LeTourneau JC, Sheehan MK, Armstrong J, Bender ME, Osterholm MT. A look-back investigation of patients of an HIV-infected physician. Public health implications. N Engl J Med 1991;325(20):1406-11. DOI PubMed

14. Holodniy M, Oda G, Schirmer PL, Lucero CA, Khudyakov YE, Xia G, Lin Y, Valdiserri R, Duncan WE, Davey VJ, Cross GM. Results from a large-scale epidemiologic look-back investigation of improperly reprocessed endoscopy equipment. Infect Control Hosp Epidemiol 2012;33(7):649-56. DOI PubMed 